\title{
Perceived risk factors for adolescent pregnancy in rural Paraguay
}

Sheri Patten Palmer ( $\square$ SHERI-PALMER@BYU.EDU)

Brigham Young University College of Nursing https://orcid.org/0000-0002-6994-6457

Rachel T Matthews

Brigham Young University-Provo: Brigham Young University

Sondra Heaston

Brigham Young University-Provo: Brigham Young University

Shelly Reed

Brigham Young University-Provo: Brigham Young University

\section{Research}

Keywords: Paraguay, adolescent pregnancy, risk factors

Posted Date: January 28th, 2021

DOI: https://doi.org/10.21203/rs.3.rs-152631/v1

License: @ (i) This work is licensed under a Creative Commons Attribution 4.0 International License. Read Full License 


\section{Abstract \\ Purpose}

Adolescent pregnancy creates challenges worldwide and manifests in both developing and developed countries. Little research has been done on factors contributing to adolescent pregnancy in Paraguay, especially among rural populations that also include indigenous people. Anecdotal information from these areas typifies adolescent pregnancy as high as $50-80 \%$.

\section{Methods}

A qualitative study including a semi-structured interview was conducted to explore perceived risks for adolescent pregnancy in Paraguay. Adults who work closely with adolescents in school, community activities, or health clinics were interviewed. Thematic analysis was used to identify the most common factors leading adolescents to become pregnant.

\section{Results}

The factors identified include school non-attendance, inadequate sex education, social pressure, widespread cultural acceptance, limited life opportunities, and poor communication. In addition, participants identified possible interventions to mitigate the perceived risk factors.

\section{Conclusions}

Among possible interventions, the most voiced method was to provide culturally appropriate school-based comprehensive sex education. Such education based on the internationally acclaimed guidelines from the WHO and UNESCO could be culturally modified. It is appropriate to include families in the teaching as the Paraguayan minister of education has proclaimed the traditional family will play a role in the upcoming reform of sex education.

\section{Introduction}

Adolescent pregnancy affects all nations to varying degrees. This single event in a young girl's life impacts every aspect of her future. Some of the troubling consequences of adolescent pregnancy are poor obstetric and perinatal outcomes, decreased socioeconomic outlook, and negative cognitive effects on the baby. According to the World Health Organization (WHO) about 12 million girls aged 15 to 19 and some 777,000 girls under 15 give birth every year-most in low- and middle-income countries (1). Comparatively, in 2017, the Center for Disease Control (CDC) found that 18.8 out of every thousand girls 15-19 years of age in the United States had given birth (2), while in Paraguay in 2018, the birth rate for this age group was 70.182 out of every thousand (3), over three times the rate for this age group in the United States. Research on early pregnancy and its implications in Paraguay is sparse with anecdotal evidence implying the challenge is acute. The purpose of this paper is to identify risk factors behind adolescent pregnancy and determine possible interventions as identified by youth leaders in a rural part of Paraguay.

\section{Background}

In South America, adolescent pregnancy is particularly prevalent and affects much of the population. In 2013, out of all the world's regions, the region of Latin America and the Caribbean has shown the least progress in decreasing adolescent pregnancy. The region was also noted as having the highest rate of pregnancies in the world among girls less than 15 years old (4). Considering research from surrounding countries, a study in Bolivia, Colombia, the Dominican Republic, Haiti, and Peru found adolescent pregnancy rates have remained the same or even increased (Colombia and Peru) over the last two decades (5). In addition, women younger than 20 years old in the poorest sections of these countries are at least twice as likely to report early pregnancy. Another study indicated the countries of Honduras, the Dominican Republic, Colombia, Peru, and Guatemala ranked second highest in adolescent birth rate globally (6). Out of the United Nations Sustainable Development Goals, 3.1, 3.2, 3.7, and 5.6, all are directed to improving health and well-being of females, including adolescents, and their children (7). One study states the Latin American countries are currently on a negative trend to not achieve these sustainable development goals on adolescent pregnancy by 2030 (8). The concept of "machismo", which is a strong sense of masculine pride (9), is also an important factor in Latin America where previous studies have shown its relation to risky sexual behaviors (10).

Worldwide, the risk for pregnancy of those living below the poverty line can be attributed to a lack of resources and knowledge of the importance in teaching sex education (6). Risk factors specific to Central and South American countries were identified through previous research $(11,6)$ which include low income, early sexual contact, multiple sexual partners, decreased parental supervision, and childhood abuse. Additionally, family members who have experienced adolescent pregnancy themselves can increase the likelihood of youth following the same path. Other risk factors include failing to use contraceptives and not receiving proper education regarding reproduction and contraception $(12,13,14,15)$. Child maltreatment and bullying are additional identified risk factors (16). Worldwide, the risk for pregnancy of those living below the poverty line can be attributed to a lack of resources and knowledge of the importance in teaching sex education (6).

Adolescent pregnancies may have long-lasting consequences on both mother and child. A systematic review from Brazil showed various negative outcomes of adolescent pregnancy. The complications dealt more commonly with the newborn, which included prematurity, low birth weight, and mortality. However, there are also maternal complications such as pre-eclampsia, eclampsia, hemolysis-elevated liver enzymes-low platelet count (HELLP) syndrome, abortion, 
urinary infection, and premature rupture of the membranes (12). Pregnancy-induced hypertension, preterm labor, operative delivery, and stillborn babies were other maternal complications encountered (17).

Detrimental physical and cognitive outcomes often coincide with drastic socioeconomic effects such as dropping out of school, facing poor living conditions, managing single-parent households, and falling into poverty $(18,19)$. In addition, children from adolescent mothers are more prone to developmental delays and behavioral disorders as they grow (20). Chaaban and Cunningham (3) wrote a paper for the World Bank that measured the economic gain of investing in girls. They estimated by using metrics from expected wage earnings from females compared to that of adolescent mothers, adolescent pregnancy costs Paraguay over 63 million dollars per year. This is a significant amount of money that could be repurposed to help the country progress in significant ways

Due to the high adolescent pregnancy rate in Paraguay and accompanying negative consequences to mother and baby, this is a challenge worth investigating. The scope of the situation in Paraguay may be better understood if risk factors are more clearly identified. Information from this study will allow future research or interventions to efficiently focus on those adolescents most at risk in Paraguay.

\section{Methods}

The researchers used a descriptive method using semi-structured interviews to discover contributing risk factors for adolescent pregnancy. In addition, possible solutions for decreasing the incidence of pregnancy were queried from the participants. The study population was Paraguayan adolescents in a rural community, including indigenous youth from Qom and Guarani cultures.

Institutional review board approval from the home university, written approval from the local non-government organization [NGO], approval from the individual schools, and oral approval from individual research subjects were obtained prior to initiating the study. Participants were asked to express their opinions, observations, and understanding of the risks, causes, and occurrence of adolescent pregnancy within their communities. The interviews were given in the Spanish or indigenous language (using translators as needed) and digitally recorded. No physical or monetary compensation was given for participation in the study. Data collection continued until saturation was reached, with sufficient data collected and no further coding being feasible (21). Researchers conducted 39 interviews in the Spanish, Qom, or Guarani languages.

\section{Sample}

A sample of community leaders was used, which included educators and healthcare personnel (many of whom themselves were once adolescent mothers). These leaders were chosen due to their close work or association with adolescents. The sample included snowball sampling as the researchers asked local leaders to refer people who qualified for inclusion. The NGO contacted the local leaders and set up appointments. The interviews took place in schools, offices, clinics, or homes for the interviewees' convenience.

\section{Interview guide}

A semi-structured interview guide was used during the interviews. Questions were derived and modified from a previous qualitative research study conducted in Paraguay (22). The guide included questions such as "Where do couples go to spend time together?" and "When youth are thinking about becoming sexually active, where do they go for information and/or protection?" After an initial interview guide was constructed, it was sent to a few members of the NGO in Paraguay, where it was reviewed and translated and was modified to be culturally sensitive.

\section{Data Analysis}

Interviews using the semi-structured interview guide were recorded, transcribed in Spanish, and then translated to English by certified bilingual (in Spanish and English) members of the research team. In accordance with the Huberman and Miles methodology of qualitative analysis (23) research team members read the transcripts separately. Preliminary themes were formed by first identifying significant statements and then formulating meanings and clustering these statements into themes. These preliminary themes were categorized into descriptive risks and validated by using a representative group consisting of some of the original participants to confirm findings.

\section{Results}

The researchers conducted 39 interviews. Participants included 12 males and 27 females, all of whom had occupations such as teachers, principals, healthcare personnel, ethnic leaders, and lay midwives. Those interviewed fell into two broad ethnic categories of indigenous (17) and nonindigenous (22) Paraguayan people.

Risk factors for adolescent pregnancy identified six major themes from this study including; school non-attendance as parents leave home to work (no supervision) or youth accompany parents on extended work leave, inadequate education about reproductive health for adolescents and their parents, social pressure from peers and leaders, cultural acceptance of early sexual debuts, limited opportunities for youth to explore extracurricular activities and pursue careers, and poor communication between youth and parents regarding sexual education (Table 1).

School non-attendance. School non-attendance was a prevalent theme mentioned by many of the school leaders from every subgroup (male, female, indigenous, and nonindigenous). Main reasons for non-attendance include parents being absent from the home (inadequate supervision) or children accompanying parents to work on the frontier for extended periods. One participant stated,

Work is still far away from the community; fathers go to work in ranches as hand laborers. They may stay for a couple of months and sometimes they take their entire family with them, even the school children 
A Paraguayan woman explained that the issue is not simply for indigenous families in this region but for indigenous families in all of Paraguay: "Both parents work, and their kids grow on their own."

Inadequate education. Many participants stated that the parents of at-risk adolescents are not willing to communicate but that they also do not know much more than their adolescent children about sexual and reproductive health. An indigenous female participant shared, "She [my mom] doesn't know how to take care of or protect herself either." Another woman shared her personal experience about a male friend's unwanted advances in her adolescence: "I didn't even know if he wanted to rape me, and I didn't even know what rape was. Rape is a new word for me."

Social pressure. Social pressure from male peers was apparent in several of the interviews, with one of the strongest examples coming from an indigenous woman: "He came up to me and strongly grabbed me and said, 'You have to have sex with me."' One male participant confirmed the pressure males put on females to engage in risky sexual behavior by stating, "Women say that men many times do not want to use a condom and that type of thing." Along with feeling social pressure, youth also felt shame in obtaining any type of contraception. Health clinic personnel mentioned that boys and girls are embarrassed to come to the clinics to ask for free condoms or birth control. Younger leaders pointed out that the clinic workers might act in a demeaning way towards the youth. Additionally, the fact that there is a male gynecologist at one of the clinics was an obstacle for girls and women seeking contraceptive care, due to the cultural taboo of talking to a man about the topic.

Cultural acceptance. One nonindigenous participant epitomized the issue by saying, '"My mother had me at 14 so why wouldn't I [have a baby]?' This is just a cycle that reproduces itself." Depending on the community, participants estimated that, between 15 and 17 years old, most of the youth pair off into serious relationships, often resulting in pregnancy. Each of the previously stated themes contributes to the cultural normalization of early pregnancy.

Limited opportunities. One participant stated,

I believe that the risk to an adolescent, number one, is not having any alternatives. That is to say, "I am not going to continue in school. I should simply be with my boyfriend and let him provide for me."

Many participants shared this perspective. With few career options to work towards, especially for the adolescents growing up in rural areas, an increasing number of adolescents do not work or go to school. Instead, they find themselves becoming parents and stepping into adult roles at an earlier age.

Poor communication. One of the most prevalent themes related to high rates of adolescent pregnancy was lack of education and communication in the home regarding sexual and reproductive health. This deficiency was mentioned by both indigenous and Paraguayan subgroups and was mentioned more often by females than by males. One indigenous woman stated, "No one ever told me about sex or how to protect yourself." A Paraguayan teacher at a school with primarily indigenous students expressed her concerns about the lack of communication in families. She said, "They are going to ignore the topic and they are going to say their daughter still isn't having sexual relations even though they are having them. ... They don't talk very much between family members.”

\section{Possible Solutions}

Study participants proposed several possible solutions (Table 2). The most common proposals included improving reproductive education, maximizing available resources, empowering Paraguayan women, and providing family support. Improvement of reproductive education was emphasized in nearly every interview, with a great emphasis placed on teaching boys and girls separately to increase their receptiveness to teaching.

Additionally, participants emphasized teaching youth to use contraceptives correctly, which would help maximize the use of available resources. In Paraguay, condoms and other reproductive healthcare services are completely free to the public yet still underutilized for a variety of reasons. The issue of shame or embarrassment felt by youth in seeking contraceptive care or sex education should be addressed. This could be addressed by opening dialogue about sexual maturation and education in schools, churches, and clinics, as well as at home.

Empowering women, setting goals, and increasing self-esteem through knowledge and education have proven effective in decreasing adolescent pregnancy in other cultures (24). One female participant stated, "When a girl has more self-esteem and more information about how to take care of herself and she has high goals, she takes better care of herself and she has less possibility of getting pregnant." Participants that mentioned this solution felt that setting goals and looking forward to future possibilities would protect adolescents.

Finally, family education is a crucial part of the solution. Parents, youth, and caregivers need to receive training due to the previously discussed multigenerational deficiencies in reproductive knowledge. One participant stated, "The solution to this problem would be greater training for the family about this topic. The mothers also need training." The most effective solutions will include a plan to educate the entire family unit. Participants mentioned improving communication between parents and youth and enhancing family support as methods to help prevent adolescent pregnancy. Adolescent pregnancy may continue unfettered until family units (youth and parents) are educated and on the same page in terms of information and communication about these topics.

\section{Discussion}

Of the general identified risks for adolescent pregnancy in the world, a few seemed unique to this region of Paraguay. Poverty is pervasive with 22.2\% (2015) of the population living below the poverty line (25). Numerous studies have shown a direct link between poverty and adolescent pregnancy $(12,13,14,15)$. This creates a large group of adolescents in Paraguay who are at risk for pregnancy simply because of their economic status.

The effects of poverty can be multi-dimensional, but for this study seem to affect adolescent pregnancy in three ways: parental absence causing unsupervised children, children leaving school to work, and decreased education and literacy rates. In rural Paraguay it is common for one or both parents to work in the city or further out in the frontier, oftentimes for extended periods. This results in lack of supervision of children in the household sporadically or long-term.

Page $4 / 9$ 
In developing countries, including Paraguay, poverty was shown to have a statistically significant effect on an increased prevalence of child labor (26). Child labor is pervasive in Paraguay (27), while $35 \%$ of adolescents drop out of school to work to improve household income (28). Child labor may increase the risk of early entrance into adult roles before children are emotionally or physically ready; this may contribute to early sexual behaviors leading to early pregnancy.

While parental absence and poverty are risk factors for pregnancy it also affects education rates of children. Either the children are left home with older siblings who do not encourage attendance at school, or the children go with the parents to the frontier. Sex education curriculum in Paraguay has changed drastically over the last decade with opposition from faith groups. Implementation of sex education has been stymied since at least 2015 as there has not been a consensus on the educational framework (30). The previous sex education courses used in Paraguay were banned by the minister of education in 2019 on the grounds that it suggests age-inappropriate activities and fosters a liberal view of sexual identity. In addition, the minister has stated that the traditional family will play a role in the upcoming reform of sex education (30). This has left a gap in this important thread of education in the schools among the adolescents. In addition, general education is a challenge as shown in a study of Paraguay's education rates published in 2019 (28) states $97 \%$ of children 6-14 years old attend primary school, but the percentage drops to $78 \%$ of adolescents $15-17$ years old. The rates of attendance decrease even more in the rural areas to $71 \%$. In addition, the rural areas of Paraguay are inhabited by large populations of indigenous people and the illiteracy rate is $10 \%$ in these areas as compared to $3.5 \%$ in urban settings (28). These factors of insufficient sex education in the schools and challenging general education rates as children get older may account for a decrease in knowledge about sexual risks and consequences. This may be heightened for those adolescents who are indigenous and/or live rurally. The lack of education and extracurricular opportunities may give adolescents more opportunities to experiment and leave them with a greater desire to find a partner and get out of the house.

As in nearly every culture, social pressure plays a strong role in early sexual debuts and increased adolescent pregnancy in Paraguay. Along with social pressure, forced pregnancy is an issue in Latin America. A report on forced pregnancy (2016) says that "tens of thousands of girls in Latin America...become pregnant against their will" (29). The report further states that in contrast to pregnancies among girls 15-19 years old which are usually from early sexual initiation, the majority of pregnancies among younger girls are the result of sexual violence perpetrated by family members, acquaintances, neighbors, or strangers (29).

While the adolescent age is fraught with continual social peer pressure, interestingly, our study showed social pressure also occurring from people recognized as healthcare workers in the community. Interviews with some health clinic personnel in Paraguay showed a discrepancy between what youth felt and what health personnel perceived regarding their lived experiences. Personnel said they encouraged youth to seek help and education from the clinics, yet leaders commented that adolescents felt belittled and shamed when they went to the clinic. A few comments explained how a new health worker, who was male, had ostracized the entire female community from this health clinic. Adjusting the environment of the clinics to be youth centered is critical in increasing availability of resources and information. Clinics should explore solutions for increasing adolescent access to resources for sexual and reproductive health. Successful strategies for identifying resources may include using text messages, and face-to-face interaction with peer mentors.

Another risk factor unique to this location was a pervasive lack of opportunities for youth in both social and economic realms. In this rural area of Paraguay, isolation can be the norm and interaction with urban life is minimal. Youth centers, libraries, shopping areas, parks, and movie theaters are across the river in central Asuncion, as are community-based activities. With few career options to work towards, especially for the adolescents growing up in rural areas, an increasing number of adolescents do not work or go to school. Instead, they find themselves becoming parents and stepping into adult roles at an earlier age.

Cultural acceptance of adolescent pregnancy has existed for generations. There has been strong cultural belief that due to the War of the Triple Alliance (1864-1870) which killed up to $70 \%$ of the Paraguayan male population, out-of-wedlock pregnancies have been the norm (31). In addition, cultural traditions are strong and prominent, often undiluted by outside influences. As a result, many of the indigenous communities have kept to themselves, so pairing off early has been expected. Participants felt that improving the outlook for youth through goals, self-esteem, and achievement would also help in decreasing adolescent pregnancy.

Finally, challenges with communication about sex between parents and adolescents is common and was the most pervasive theme of the study. This issue may stem from a multigenerational deficiency of adequate reproductive health knowledge. In addition, talking about sex is taboo in many cultures, including Latin America (32). The adolescents as well as many of the adults we encountered were genuinely surprised we were studying pregnancy and sex. A few interview participants were shy and reserved when talking about the subject. Another challenge with communication is the differences in languages themselves among the people of Paraguay. Guarani is the primary language, especially in the household, while Spanish is largely used in schools and among adolescents. This situation has caused ambivalent feelings as teachers struggle to teach students in Spanish while the children come from largely Guarani speaking families (33). In addition, parents may not feel comfortable using the Spanish language for words they are only accustomed with in Guarani.

\section{Limitations}

The study focused on small rural communities, which could be a limitation; however, the provision of thick, rich descriptions about the phenomena of adolescent pregnancy may help to confer transferability to a larger population. Another limitation is that adolescents themselves were not interviewed to determine their personal experiences with the risks for adolescent pregnancy. Further studies are warranted to investigate the lived and personal experiences of adolescents in this area of Paraguay. Replication of this study in other rural indigenous or nonindigenous communities, especially in Latin America, would also broaden the understanding of factors contributing to adolescent pregnancy in these populations.

\section{Conclusions}

As demonstrated by the global prevalence of adolescent pregnancy throughout history, many challenges are inherent in attempts to reduce this phenomenon. People who work with adolescents and understand cultural humility need to be sensitive to the dynamics of how culture plays a large role in sex and 
maturation. Research has shown that education on sex and maturation can help adolescents make better life choices. Thus, interventions that combine sex education with other culturally sensitive initiatives are important. Based on some of our findings on risks for adolescent pregnancy, specific and practical applications may include the following:

1. Teach adolescents, in a culturally sensitive and ethical manner, about the dangerous physical consequences adolescent pregnancy can have on both mother and child.

2. Teach the specifics about sexual and reproductive healthcare to adolescents in the classroom. Separating boys and girls may encourage open discussion.

3. Include family and parents in the teaching process, either by sending home topics for discussion or by teaching family members in a community setting.

4. Teach comprehensive sex education based on the principles of the WHO and UNESCO guidelines $(34,35,36)$.

5. Explore and create viable options for adolescents to gather and grow, whether with planned extracurricular activities or safe community/public locations that enhance social connections.

6. Implement a life-strategies curriculum into public schools that enables adolescents to research and discuss goals pertinent to their age. This curriculum would also help adolescents envision and pursue various options for their future life goals and achievements.

Creating interventions that are culturally appropriate is key to success in any community-based program. Combining efforts with a local NGO and community leaders may improve chances of success in addressing the risks for adolescent pregnancy. Meaningful change takes time and is based on strong ties and trust within cultures and communities. Finally, preserving beneficial cultural influences within populations is a delicate but essential task.

\section{Declarations}

\section{Ethics approval and consent to participate}

Ethics approval was obtained from the home university (Brigham Young University, IRB \# E18224, irb@byu.edu), approval was also obtained from the Nongovernment Organization, Fundacion Paraguaya, approval was obtained from the Schools in Belen, Cerritos, and San Pedro, Paraguay, approval and consent were obtained from all participants in the study.

\section{Consent for publication}

This manuscript does not contain any individual person's data in any form.

\section{Availability of data and materials}

Data supporting the results found in this article are available from the primary author on reasonable request.

\section{Competing interests}

The authors declare that they have no competing interests.

\section{Funding}

Funding for part of this research was granted from the Experiential Learning funds from Brigham Young University. Funds were used for travel to collect data, analyze and interpret the data.

\section{Authors' contibutions}

The corresponding author declares that all listed authors have been involved in all parts of the research study and written manuscript. Furthermore, they have approved of the final written copy and tables.

Sheri P Palmer-primary author and researcher

Sondra Heaston-author and researcher

Rachel T. Matthews-author and researcher

Shelly Reed-author, researcher, and qualitative method integrity

\section{Acknowledgements}

Cortney W. McFarlane, Rebecca D. Anderson, Megan Hancock, Kaylee Hodgson, Julia L. Kemsley 


\section{References}

1- World Health Organization. Adolescent pregnancy. Fact sheet. 2020 Jan. https://www.who.int/en/news-room/fact-sheets/detail/adolescent-pregnancy

2- Martin, J. A., Hamilton, B. E., Osterman, M. J. K., Driscoll, A. K., \& Drake, P. National vital statistics reports. 2018 Nov 7; 67(8), 1-50.

https://www.cdc.gov/nchs/data/nvsr/nvsr67/nvsr67_08-508.pdf

3- Chaaban, J., \& Cunningham, W. Measuring the economic gain of investing in girls. The World Bank. 2011 Aug.

https://documents.worldbank.org/en/publication/documents-reports/documentdetail/730721468326167343/measuring-the-economic-gain-of-investing-ingirls-the-girl-effect-dividend

4- Caffe, S., Plesons, M., Camacho, A.V., Brumana, L., Abdool, S. N., Huaynoca, S., Mayall, K., Menard-Freeman, L., de Francisco Serpa, L. A., Gomez Ponce de Leon, R., \& Chandra-Mouli, V. Looking back and moving forward: Can we accelerate progress on adolescent pregnancy in the Americas? Reproductive Health, 2017; 14(1), 83. https://doi.org/10.1186/s12978-017-0345-y

5- Neal, S., Harvey, C., Chandra-Mouli, V., Caffe, S., \& Camncho, A.V. Trends in adolescent first births in five countries in Latin America and the Caribbean: disaggregated data from demographic and health surveys, Reproductive Health, 2018; 15:146. https://doi.org/10.1186/s12978-018-0578-4

6- Dongarwar, D., \& Salihu, H. M. Influence of sexual and reproductive health literacy on single and recurrent adolescent pregnancy in Latin America. Journal of Pediatric and Adolescent Gynecology, 2019; 32(5), pp 506-513. http://dx.doi.org/ 10.1016/j.jpag.2019.06.003

7- United Nations. Transforming our world: the 2030 Agenda for Sustainable Development, New York: United Nations, New York, 2015

https://sustainabledevelopment.un.org/content/documents/21252030\%20Agenda\%20for\%20Sustainable\%20Development\%20web.pdf, accessed 8 December 2020.

8- Gianella, C., de Assis Machado, M. R., \& Peñas Defago, A. What causes Latin America's high incidence of adolescent pregnancy? CMI Brief, 2017; 16(9). https://open.cmi.no/cmi-xmlui/handle/11250/2475446

9- Terrazas-Carrillo, E., \& Sabina, C. Dating violence attitudes among Latino college students: an examination of gender, machismo, and marianismo. Violence and victims, 2019; 34(1), 194-210.

10- Darre, S., Jerves, E., Castillo, J. \& Enzlin, P. Evidence-based Approaches to Sexuality Education: A Global Perspective. Ed. Ponzetti, J. Jr., 2015; Routledge, NY.

11- Borges, A. L. V., do Nascimento Chofakian, C. B., Sato, A. P. S., Fujimori, E., Duarte, L. S., \& Gomes, M. N. Fertility rates among very young adolescent women: Temporal and spatial trends in Brazil. BMC Pregnancy and Childbirth, 2016; 16(1), 57. http://dx.doi.org/10.1186/s12884-016-0843-x

12- Azevedo, W. F. D., Diniz, M. B., Fonseca, E. S. V. B. D., Azevedo, L. M. R. D., \& Evangelista, C. B. Complications in adolescent pregnancy: systematic review of the literature. Einstein (São Paulo), 2015; 13(4), 618-626.

13- Makiwane, M., Gumede, N. A., \& Molobela, L. Initiation of sexual behaviour and early childbearing: Poverty and the gendered nature of responsibility amongst young people in South Africa. Journal of International Women's Studies, 2018; 19(5), 209-226. http://awdflibrary.org:8080/handle/123456789/697

14- Smith, C., Strohschein, L., \& Crosnoe, R. Family histories and teen pregnancy in the United States and Canada. Journal of Marriage and Family, 2018; 80(5), $1244-1258$

https://doi.org/10.1111/jomf.12512

15- Yakubu, I., \& Salisu, W. J. Determinants of adolescent pregnancy in sub-Saharan Africa: A systematic review. Reproductive Health, 2018; 15 (1), 15. https://doi.org/10.1186/s12978-018-0460-4

16- Charlton, B. M., Roberts, A. L., Rosario, M., Katz-Wise, S., Calzo, J. P., Spiegelman, D., \& Austin, S. B. Teen pregnancy risk factors among young women of diverse sexual orientations. Pediatrics, 2018; 141(4). e20172278. http://dx.doi.org/ 10.1542/peds.2017-2278

17- Shaikh, F., Abbas, S., Sultana, F., Yousfani, S., \& Hasan, T. Adverse outcome of a teenage pregnancy. Journal of the Liaquat University of Medical and Health Sciences, 2016; 15(4), 179-182. doi:10.22442/jlumhs.161540489 https://www.lumhs.edu.pk/jlumhs/Vol15No04/pdfs/05.pdf

18- Diaz, C. J., \& Fiel, J. E. The effect(s) of teen pregnancy: Reconciling theory, methods, and findings. Demography, 2016; 53(1), 85-116.

https://doi.org/10.1007/s13524-015-0446-6

19- Lang, K., \& Weinstein, R. The consequences of teenage childbearing before Roe v. Wade. American Economic Journal: Applied Economics, 2015; 7(4), 16997. http://dx.doi.org/10.1257/app.20130482

20- Goossens, G., Kadji, C., \& Delvenne, V. Teenage pregnancy: A psychopathological risk for mothers and babies? Psychiatria Danubina, 2015; 27(1), 499503. https://pubmed.ncbi.nlm.nih.gov/26417827/

21- Ness, L. R. Are we there yet? Data saturation in qualitative research. Qualitative Report, 2015; 20(9), 1408-1416. 
22- Andes, K.L, \& Cisneros Puebla, C.A. Sexual and reproductive health in adolescents in Asunción, Paraguay: a qualitative needs assessment. In Adolescent sexual and reproductive health in Asunción, Paraguay: a qualitative needs assessment. 2009; CEPEP.

23-Hashimov, E. Qualitative Data Analysis: A Methods Sourcebook and The Coding Manual for Qualitative Researchers: Matthew B. Miles, A. Michael Huberman, and Johnny Saldaña. Thousand Oaks, CA: SAGE, 2014. 381 pp.

24- Berge, L. I. O., Bjorvatn, K., Maalim, A. M., Somville, V., \& Tungodden, B. Reducing early pregnancy in low-income countries. Towards Gender Equity in Development, Eds. Anderson, Beanman \& Platteau. A study prepared by the United Nations University World Institute for Development Economics Research. Oxford Press. 2018; UK, pp. 141-166.

https://library.oapen.org/bitstream/handle/20.500.12657/25125/9780198829591_Towards_Gender_Equity_in_Development.pdf?sequence=1\#page=166

25- The World Factbook. Paraguay. n.d. https://www.cia.gov/library/publications/the-world-factbook/geos/print_pa.html

26- Abdullahi, I. I., Noor, Z. M., Said, R., \& Baharumshah, A. Z. Does poverty influence prevalence of child labour in developing countries? International Journal of Economics and Financial Issues, 2016; 6(1).

27- Bureau of International Labor Affairs. 2019 Findings on the worst forms of child labor. https://www.dol.gov/agencies/ilab/resources/reports/childlabor/paraguay

28- Martínez, A. M. W. Política pública y paradigmas sociales: Análisis de la educación de personas jóvenes y adultas en Paraguay. (Public policy and social paradigms: Analysis of the youth and adult education in Paraguay), Revista de Education de Adultos y Procesos Formativos. Primer Semestre. 2019; 8. Pp. 5469. ISSN 0719-6997. https://www.educaciondeadultosprocesosformativos.cl/revista/wp-content/uploads/2019/12/Texto-3-Andrea-Werhle-Paraguay.pdf

29- Chiarotti, S. Girl Mothers. Forced child pregnancy and motherhood in Latin America and the Caribbean. The Latin American and Caribbean Committee for the Defense of Women's Rights (CLADEM), 2016. ISBN 78-999953-879-6-0. www.cladem.org.

https://d3n8a8pro7vhmx.cloudfront.net/equalitynow/pages/311/attachments/original/1528286922/Girl_Mothers_English_Final_To_Publish_0_\%283\%29.pdf 1528286922

30- Smits, J. Paraguay education minister bans 'libertine' gender ideology course in public schools. LifeSite. Paris correspondent. 2019. https://www.lifesitenews.com/news/paraguay-education-minister-bans-libertine-gender-ideology-course-in-public-schools

31- Alix-Garcia, J., Schechter, L., Valencia Caicedo, F., \& Zhu, S. J. Country of Women? Repercussions of the Triple Alliance War in Paraguay. CEPR Discussion Paper No. DP14752. 2020. https://ssrn.com/abstract=3598489 or http://dx.doi.org/10.2139/ssrn.3598489

32- Ivanova, O., Cordova-Pozo, K., Segura, Z. E., Vega, B., Chandra-Mouli, V., Hindin, M. J., ... \& Michielsen, K. Lessons learnt from the CERCA Project, a multicomponent intervention to promote adolescent sexual and reproductive health in three Latin America countries: a qualitative post-hoc evaluation. Evaluation and Program Planning, 2016; 58, 98-105. https://doi.org/10.1016/j.evalprogplan.2016.06.007

33- Von Streber Lee, G. Paraguay and the Complexities of a Bilingual Nation: The Contradiction of the Guarani Language as a National Symbol and its Condition of Diglossia. Encuentros, 2018; 16(1), 107-119. http://www.scielo.org.co/scielo.php?script=sci_arttext\&pid=S1692-58582018000100107

34- Women, U. N., \& UNICEF. International technical guidance on sexuality education: an evidence-informed approach. 2018; UNESCO Publishing.

35- Herat, J., Plesons, M., Castle, C., Babb, J., \& Chandra-Mouli, V. The revised international technical guidance on sexuality education-A powerful tool at an important crossroads for sexuality education. Reproductive Health, 2018;15(185), pp 1-4. http://dx.doi.org/10.1186/s12978-018-0629-x

36- UNICEF. Accelerating progress toward the reduction of adolescent pregnancy in Latin America and the Caribbean. Report of a Technical Consultation. 2016; Washington, DC, USA. https://iris.paho.org/bitstream/handle/10665.2/34493/9789275119761-eng.pdf?sequence=1\&isAllowed=y\&ua=1

\section{Tables}

Table 1: Identified Risk Factors 


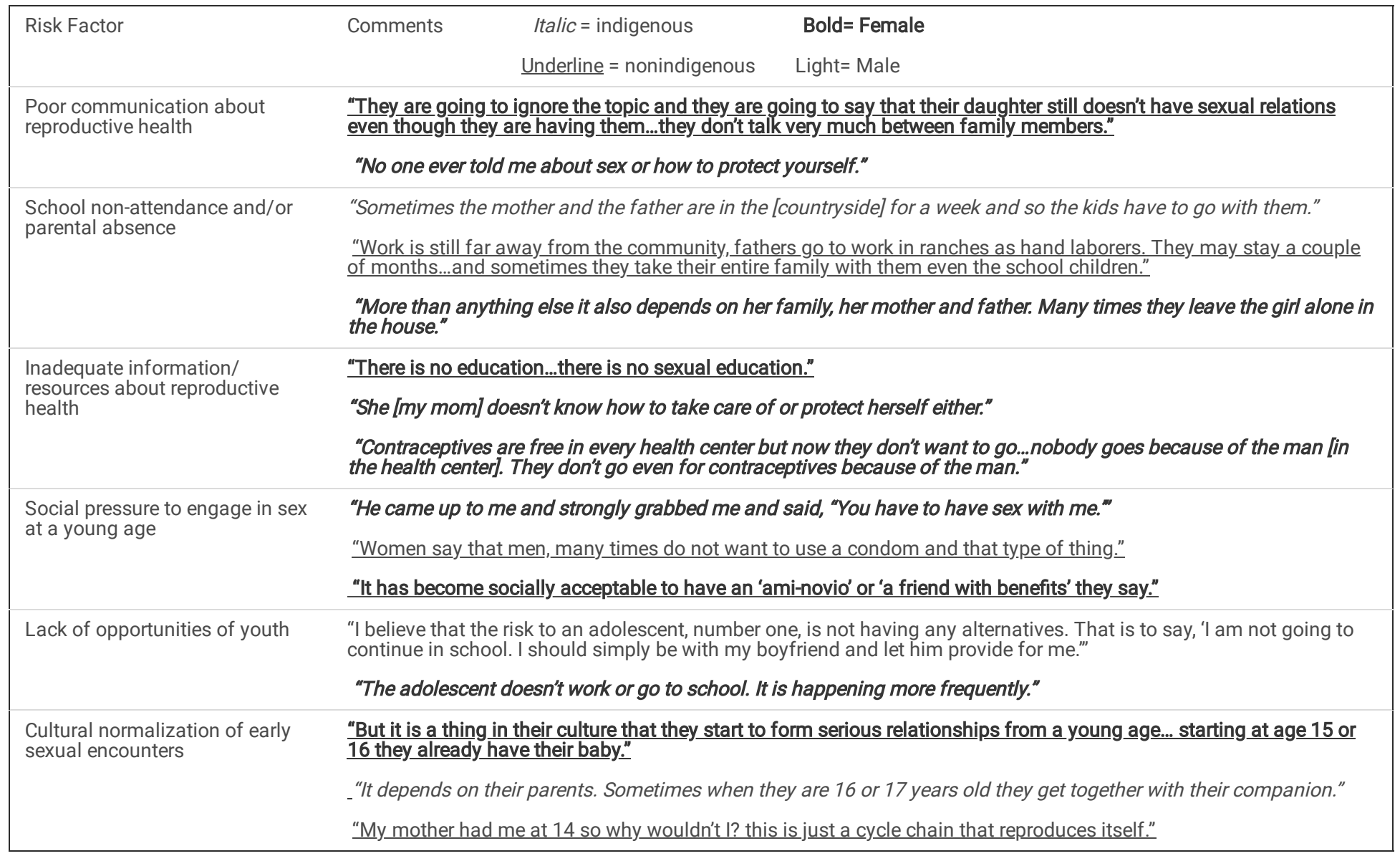

Table 2: Locally suggested solutions

\begin{tabular}{|c|c|}
\hline $\begin{array}{l}\text { Themes for } \\
\text { improvement }\end{array}$ & $\begin{array}{l}\text { Italic }=\text { indigenous } \quad \text { Bold }=\text { Female } \\
\underline{\text { Underline }=\text { nonindigenous }} \quad \text { Light }=\text { Male }\end{array}$ \\
\hline \multirow{3}{*}{$\begin{array}{l}\text { Improving } \\
\text { reproductive } \\
\text { education }\end{array}$} & $\begin{array}{l}\text { "It's important to have it with the girls and then with the boys. Separate. Because if it is together...the people in the community } \\
\text { don't talk quickly or openly. They are very timid." }\end{array}$ \\
\hline & "They need to know about the risks of sex." \\
\hline & "They need to be taught this, they need to know how to use contraceptives so that they use them correctly." \\
\hline \multirow{3}{*}{$\begin{array}{l}\text { Maximizing } \\
\text { available resources }\end{array}$} & "There has to be a joint work between the department of health and the parents." \\
\hline & $\begin{array}{l}\text { "Something important would be that the government would take measures... many of the girls are on Facebook so you now have } \\
\text { forms of communication to reach the girls directly.. }\end{array}$ \\
\hline & "Well first, focus on access to information." \\
\hline \multirow[t]{2}{*}{ Empowering women } & $\begin{array}{l}\text { "When a girl has more self-esteem and more information about how to take care of herself and she has high goals, she takes } \\
\text { better care of herself and she has less possibility of getting.pregnant." }\end{array}$ \\
\hline & $\begin{array}{l}\text { "If you still don't have children it is very important to me for you to be an example and tell them what you have done to avoid } \\
\text { having children to this point." }\end{array}$ \\
\hline \multirow{3}{*}{$\begin{array}{l}\text { Providing family } \\
\text { support }\end{array}$} & "We need to teach the parents." \\
\hline & "We need to reach out to every family and plan a day to have a discussion." \\
\hline & "The solution to this problem would be greater training for the family about this topic. The mothers also need training." \\
\hline
\end{tabular}

